\title{
0 artista
}

\section{de rádio}

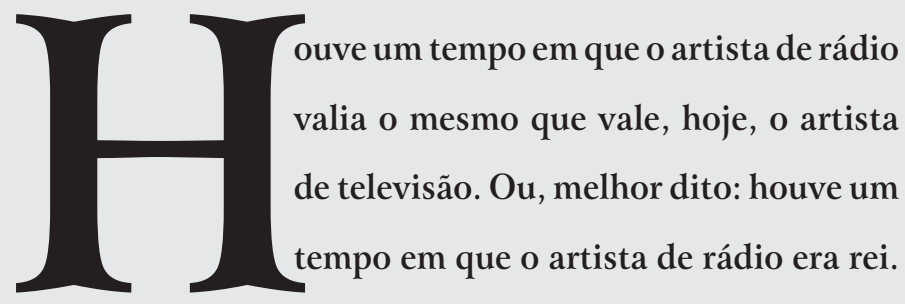

Quem pretendia ser artista de rádio precisava demonstrar aptidão para falar, cantar ou executar um instrumento. (De onde se conclui que o rótulo de "artista" era reservado àqueles que tinham afinidade com o microfone. Em relação às demais funções, dizia-se que as pessoas "trabalhavam no rádio".)

Uma vez dotado do poder extraordinário de se comunicar ao mesmo tempo com um sem-número 
de pessoas, $\mathrm{o}$ artista de rádio as encantava à maneira dos mágicos - não fosse o rádio, por si só, pura magia!

A carreira de um artista de rádio começava no momento mesmo em que ele dizia um "a" ou emitia uma nota musical diante do microfone. Mas podia ser imediatamente abortada se ele não tivesse um certo quê. Não apenas a cara bonita e o charme que, atualmente, atraem os caça-talentos da TV; e, sim, algo mais sutil, misterioso mesmo, que só o microfone, transmudado em detector de mentira, podia conferir.

Para falar no rádio, o essencial era possuir uma "voz microfônica", isto é, um timbre que não ofendesse o delicado cristal que, ao vibrar, liberava as palavras para sua viagem pelas ondas sonoras. Se o objetivo era o canto ou a execução de algum instrumento, afinação e ritmo eram fatores decisivos. Em todos os casos, porém, uma vez credenciado a chegar perto do microfone, o candidato a artista de rádio tinha de enfrentar o indefectível teste.

Por exemplo: o speaker em potencial entrava sozinho num estúdio diminuto, levando algumas folhas datilografadas numa pasta, que só devia ser aberta quando the fizessem um sinal através do vidro duplo que separava aquele compartimento estanque da sala de controle. Encerrado num verdadeiro aquário (outro não era, por sinal, o apelido desse tipo de estúdio) e oprimido pelo inusitado silêncio, o sujeito suava frio, tremia e respirava com dificuldade, enquanto aguardava a ordem para abrir a pasta e ler, de primeira, o seguinte: textos comerciais de diferentes estilos; notícias sobre diversos assuntos; uma pequena crônica ou comentário jocoso; um soneto de Olavo Bilac; um boletim de agência noticiosa in- 
ternacional, recheado de nomes próprios e termos predominantemente ingleses e franceses; títulos originais de músicas estrangeiras, populares ou clássicas, com os nomes dos respectivos autores; e, por fim, um texto com frases quilométricas - uma autêntica prova de fôlego. Em seu conjunto, esse tipo de teste qualificava o candidato a ler notícias e mensagens comerciais, apresentar programas, realizar entrevistas e reportagens, inclusive no campo esportivo; ou, ainda, representar. Neste último caso, o candidato a radioator tinha o privilégio de ler o script antes de pôr à prova seu talento, num diálogo com um artista da casa. Seu início de carreira era, também, mais tranqüilo: como fazia parte de uma equipe, tinha menos responsabilidade que o indivíduo largado sozinho diante do microfone; quase sempre começava em pequenos papéis, com poucas falas, do tipo: "Doutor, chegou um telegrama"; e, gradualmente, à medida que conquistava a confiança do diretor, passava a ser escalado para representar personagens mais importantes.

Em relação ao cantor ou instrumentista, o teste inicial podia ser público - num programa de calouros, por exemplo - ou na sala de ensaio, na presença do todo-poderoso diretor musical, às vezes assistido por músicos da casa, prontos a torcer o nariz ao menor deslize do novato. Para a aprovação do cantor, particularmente, eram levados em conta, além da qualidade vocal, outros predicados, como simpatia, boa aparência e um gosto aceitável no vestir, uma vez que os artistas se apresentavam com a própria roupa. O cantor ou a cantora era, também, a figura principal dos programas de auditório, quando este constituía o mais importante elo entre a estação de rádio e o ouvinte. Como ainda não existia uma pesquisa sistemática de audiência, o auditório era o único "ibope" capaz de medir a popularidade dos programas e dos artistas. Daí a importância que os donos das rádios davam ao auditório, a ponto de, não raro, nele investirem mais que na área técnica. De qualquer forma, o resultado dessa política não poderia ter sido melhor, quando se sabe que nos auditórios das rádios surgiram e se consagraram grandes intérpretes da nossa música. Esse fenômeno, digno de figurar num estudo sobre os ingredientes formadores da cultura popular, registrou-se com maior ênfase na segunda metade de 1930 e na década seguinte. E não foi por outro motivo que a televisão, desde seus primeiros dias, não hesitou em copiar a bem-sucedida fórmula do programa de auditório.

$\mathrm{O}$ auditório, contudo, não era uma vitrine apenas para os cantores. Nele conviviam, em perfeita harmonia, animadores, humoristas, solistas, orquestras, conjuntos vocais e instrumentais - enfim, uma mescla de artistas de todos os gêneros. Conforme o estilo da emissora, os programas podiam conter desde música popular variada, humor, concursos, desfile de calouros, brincadeiras, até música lírica, provas de conhecimento geral, apresentação de artistas internacionais, etc. Para cada tipo de programa, havia recursos técnicos adequados: vários microfones, fixos em pedestais ou suspensos por cabos na altura requerida, graças a um servomotor controlado a distância; tratamento acústico; tablados, onde se instalavam a grande orquestra - com até 50 figuras -, conjuntos e corais; um lugar de honra para o piano de meia cauda ou o órgão elétrico; iluminação direcional, quase tão eficiente quanto a dos teatros. Para o público, que não pagava ingresso, mas muitas vezes só era admitido mediante convite retirado previamente, a sensação era, mesmo, de estar num teatro, pois não faltava nem o pano de boca, que se abria aos primeiros acordes do prefixo do programa. Havia diferentes tipos de auditório, uns mais luxuosos e quase sempre com um número menor de poltronas, e outros, relativamente simples, feitos para receber um público mais numeroso. Nos primeiros, os frequientadores só podiam entrar usando paletó e gravata - como, aliás, era praxe em muitos cinemas -, enquanto nos outros não havia tal exigência.

Quanto à decoração, esses autênticos templos do rádio se apresentavam com cortinas de veludo, iluminação indireta e plantas ornamentais, ou podiam até mesmo ostentar obras de arte, como no caso do auditório de uso comum das rádios Tupi e 
Difusora, na "Cidade do Rádio", em que era dado ao público contemplar telas de Portinari. Por outro lado, para se apresentar no auditório de uma Rádio Gazeta, que se autodenominava "A Emissora de Elite", o artista, ou quem quer que pisas se o palco, tinha de usar traje a rigor; e não sem alguma razão, pois ali desfilava com freqüência o respeitável elenco operístico do Teatro Municipal. Já a Rádio Kosmos primava pela originalidade: em seu auditório, os espectadores, acomodados em poltronas de vime ao redor de mesinhas postas para o chá, colocadas diante do palco, assistiam a espetáculos tão deliciosos quanto a aromática bebida que lhes era servida por gentis garçonetes. Contrastando com tamanha sofisticação, no despojado auditório da Rádio Cruzeiro do Sul, era a presença maciça de público que refletia o insofismável sucesso da emissora.

$\mathrm{O}$ auditório, pequeno ou grande, com aparência de teatro ou de elegante salão de chá, foi, sem dúvida, um fator de importância vital para as emissoras. Talvez por não ter condições, nesse particular, de competir com as concorrentes, a Rádio Excelsior tratou de contornar tal deficiência adotando este slogan: "O maior auditório do Brasil - uma poltrona em cada lar!".

Até aqui, objetivou-se retratar o rádio dos velhos tempos, relembrar suas convenções e, com premeditada intenção, estabelecer clima propício ao aparecimento do principal: $u m$ artista de rádio - alguém capaz de representar de corpo e alma o espécime em questão. E vamos encontrá-lo, não num palco iluminado diante de numerosa platéia, mas no “aquário" que era o estúdio da Rádio Cultura, em 1939.

A esse tempo, o rádio comercial, modelo importado dos Estados Unidos (1), já havia se consolidado, passando a merecer uma fatia das verbas de publicidade. As estações de rádio se espalhavam e sua implantação em qualquer cidade que se prezasse era quase obrigatória. Por outro lado, os programas das principais emissoras tornavam-se cada vez mais sofisticados, exigindo um elenco numeroso e variado. A concorrência se acirrava; era preciso modernizar o equipamento e popularizar os artistas a fim de garantir um lugar na preferência dos ouvintes, e isso tinha seu preço. Algumas emissoras, porém, chegaram ao limiar do grande boom da radiodifusão brasileira, registrado na década de 40, mantendo sua posição graças a soluções que haviam descoberto e mantido, ano após ano. Conseguiam sobreviver, em função de idéias - e do talento necessário a sua consecução - que, no caso da Cultura, tinham o respaldo de um artista excepcional: Nhô Totico.

Desde que começou a atuar, em 1933, Nhô Totico, com seu humor sem paralelo, conquistou rapidamente uma legião de ouvintes, não só na capital paulista como no estado e em boa parte do território nacional. Na época, era comum a recepção em ondas curtas, até mesmo onde não havia rede elétrica, suprindo-se a falha com o uso de baterias de automóvel. A cobertura de grande alcance aumentava e diversificava a audiência de tal forma, que os artistas das principais emissoras, situadas nos grandes centros, ganhavam uma projeção comparável àquela desfrutada, hoje, pelos grandes nomes da televisão.

Pois Nhô Totico era um ídolo desse porte, não só para as crianças, como para o público em geral. Mas, afinal, quem era e como surgiu esse tal Nhô Totico?

Vital Fernandes da Silva - esse era seu nome verdadeiro - nasceu em Descalvado, estado de São Paulo, em 1903, filho de pai baiano e mãe italiana. “João Baiano", como era apelidado seu pai, assim que desembarcou na Estação da Luz, na capital paulista, dirigiu-se à bilheteria e pediu uma passagem para "o fim da linha”. O funcionário entendeu que tal lugar era Descalvado, e lá foi parar "João Baiano". Nessa cidade, ele se casou com uma jovem nascida em Milão, de onde foi trazida pelos pais, que se estabeleceram inicialmente no Rio Grande do Sul, mas também acabaram se mudando para o interior de São Paulo. "João Baiano" era músico e executava vários instrumentos, mas preferia a clarineta. Devido à sua condição de chefe do pequeno conjunto musical que acompanhava a exibição dos

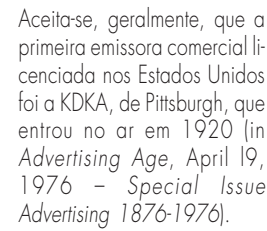

Aceita-se, geralmente, que a primeira emissora comercial licenciada nos Estados Unidos foi a KDKA, de Pittsburgh, que entrou no ar em 1920 lin Advertising Age, April 19 1976 - Special Issue Advertising 1876-1976). 
filmes mudos no cinema local, tornou-se sócio do dono do cinema. E não se tratava de um cinema qualquer, pois, além da música executada com capricho, oferecia uma "sonorização" extra: os ruídos produzidos atrás da tela por um grupo de moleques sob a direção do menino Vital, filho do maestro. Mas não foi essa sua primeira atividade "artística": aos quatro anos de idade, Vital já demonstrara seu talento precoce nas festinhas, ao imitar um equilibrista na corda bamba: enquanto o pai tocava música circense em sua clarineta, o menino abria os braços e andava na ponta dos pés sobre uma fresta das tábuas do assoalho; fingia pender para os lados e quase cair, para logo readquirir o equilíbrio - arrancando exclamações, aplausos e risos da platéia formada por parentes e amigos.

Anos mais tarde, mudando-se para São Paulo, Vital, que já adotara o cognome de "Nhô Totico", arranjou um emprego na Repartição de Águas e Esgotos e parecia destinado a uma monótona carreira burocrática. Ainda nem sonhava com o rádio, mas era considerado um "artista" no seu círculo de amizades. Sua primeira aparição pública em São Paulo se deu quando começou a participar, como animador, de eventos promovidos para ajudar as obras sociais do Mosteiro de São Francisco, situado no largo do mesmo nome, ao lado da Faculdade de Direito da USP e a pequena distância da repartição em que trabalhava. Devido a essa proximidade, não tardou a fazer amizade com os estudantes do "XI de Agosto", sendo pomposamente proclamado "humorista oficial" do grêmio. Logo depois, um dos estudantes, Enéas Machado de Assis - que cumpriria longa e destacada carreira de radialista, na ativa até hoje leva-o para a Rádio Cultura, da qual um dos proprietários e também diretor era Olavo Fontoura (2). Na hora do teste, Nhô Totico pergunta ao diretor o que deveria fazer, e este responde: “O mesmo que você faz para os estudantes”. Ojovem Nhô Totico conclui que o diretor não entendia nada de rádio, pois se ele repetisse ao microfone as brincadeiras habituais, em que costumava desancar Getúlio Vargas, a rádio fatalmen- te seria fechada. Vai, então, para o microfone e improvisa um teatrinho, interpretando todos os papéis. Não mexe diretamente com política, mas brinca com os imigrantes que constituem boa parcela da população. E foi com essa demonstração, diretamente no ar, que ele conseguiu seu primeiro contrato.

Desse dia em diante, durante três décadas, repetindo a fórmula usada no teste, ele criou as histórias e viveu os personagens da "Escolinha de D. Olinda" e "XPTO, Vila de Santo Antônio da Arrelia”, ou, simplificando, "Vila da Arrelia" - o primeiro, um programa dirigido às crianças; o segundo, feito para o público adulto.

Do começo ao fim de sua longa carreira, Nhô Totico fez do humor inteligente sua principal característica. Jamais recorreu a preconceitos ou empregou expressões grosseiras, com a intenção de chocar ou provocar riso fácil.

$\mathrm{Na}$ "Escolinha", D. Olinda, a irrepreensível e simpática professora, contracenava com um aluno português, um italiano, um árabe, um japonês e um caipira, além do zelador e de outros personagens que apareciam na sala de aula, por este ou aquele motivo. Esses tipos tornaram-se rapidamente familiares para os ouvintes, que, nas conversas, repetiam seus bordões.

Na "Vila da Arrelia", onde também predominava a mistura de povos e costumes, os diálogos criados por Nhô Totico abordavam acontecimentos recentes, no linguajar característico dos personagens, obedecendo a uma dinâmica que alternava momentos de harmonia e de conflito. A comicidade, habilmente dosada, amenizava a discussão sem comprometer a importância dos temas. Com isso, ao mesmo tempo em que se divertia, o ouvinte era levado a tirar, ele próprio, suas conclusões sobre os assuntos em foco.

Mas se o conteúdo nas histórias que inventava já era algo significativo, que dizer, então, da performance do artista ao personificar, dia após dia, ano após ano, aquele mundo de gente? A habilidade com que interpretava todos os papéis, independentemente de sexo ou idade - com uma versatilidade comparável a um desses sinteti- 
zadores que reproduzem os sons de vários instrumentos -, chegava ao máximo quando ele criava uma discussão acalorada envolvendo várias pessoas: as vozes se alternavam, numa fração de segundo, e até pareciam misturar-se. Num período que vai desde o momento em que o rádio era ainda uma promessa, até tornar-se um eficiente meio de comunicação de massa, poucos artistas alcançaram tanta popularidade quanto Nhô Totico. Não foi, portanto, sem razão que ele teve dezenas de imitadores no rádio e, mais tarde, na televisão.

Entretanto, o fato de fazer tudo de improviso, desprezando o uso de texto, acabaria por lhe causar transtornos em determinado período da vida nacional: quando a censura obrigou toda e qualquer emissora a encaminhar com antecedência, e por escrito, o que iria para o ar, um grupo de radialistas de renome teve de se responsabilizar perante as autoridades pelos programas de Nhô Totico. (A propósito, não há qualquer indício de que alguém tenha sido intimado ou preso por assumir esse risco...)

As circunstâncias do meu primeiro contato com Nhô Totico foram as seguintes: com 12 anos de idade, vindo de Ponta Grossa, Paraná, em visita a uma tia que morava em São Paulo, implorei para que ela me levasse à estação de rádio para conhecer Nhô Totico. E lá fomos os dois de um extremo a outro da cidade, por três diferentes linhas de bonde, desde a Casa Verde, até o Jabaquara, bairro em que, na época, funcionava a Rádio Cultura como um todo: estúdio, transmissor e antena.

Junto ao estúdio havia uma sala de pequenas dimensões, em que dezenas de pessoas - crianças em sua maioria - se acotovelavam. Através do visor que dividia os dois ambientes, pude ver o locutor, sentado a uma mesinha diante do microfone. Nisso, enquanto se ouvia uma música pelo altofalante, aparece Nhô Totico, que sorri e acena para o público. Todos respondem ruidosamente à saudação, enquanto ele vai para o microfone e o programa começa.

Para um menino que passava quase to- das as horas de folga (além de algumas roubadas ao tempo destinado às lições de casa) grudado no Telefunken de ondas longas e curtas, ter a oportunidade de ouvir Nhô Totico e, ao mesmo tempo, vê-lo cara a cara, foi um acontecimento único. Pela primeira vez eu deixava de ser apenas um ouvinte solitário, podia rir e ouvir as risadas de outras pessoas, como se todo mundo estivesse numa festa, e, ainda mais, desvendar o mistério da transmissão radiofônica. Quando o programa acabou e Nhô Totico deixou o estúdio, acenando outra vez para o público, as pessoas não tiveram pressa em se retirar da sala. Ficaram por ali, comentando as passagens mais engraçadas do programa - o que provocava novos risos - , como se desejassem prolongar os momentos de pura alegria que haviam experimentado. Minha admiração por Nhô Totico cresceu ainda mais a partir daquele dia, em que, desconfio, fui contagiado pelo "micróbio do rádio": alguns anos depois, inconformado com o papel de simples ouvinte, só me dei por satisfeito quando consegui um lugar na emissora da minha cidade.

Fui rever Nhô Totico quando, de há muito, ele havia se aposentado e aceitava de boa vontade o papel de "lenda viva". Falar dos velhos tempos, lembrar como era o rádio antes da televisão, enfim, contar sua vida e, a pretexto de ilustração, trazer de volta para o microfone seus incríveis personagens - tudo isso era um prazer para ele. Estávamos em 1984, e o novo encontro só podia se dar numa estação de rádio. Novamente através de um visor, dessa vez num estúdio da Rádio USP, eu acompanhava seu desempenho, como naquele dia memorável na antiga Rádio Cultura. Ele passava dos 80 anos, mas ainda era dono das mil vozes e representava com a desenvoltura de sempre os personagens da "Escolinha de D. Olinda" e da "Vila da Arrelia" - o espírito crítico aceso e os comentários afinados com os acontecimentos da atualidade.

Eu nunca mais o veria, a não ser em entrevistas na televisão. No entanto, em 1998, três anos depois de sua morte, um fato novo restabeleceu de modo inesperado minha curiosa conexão com a trajetória 
de Nhô Totico: Valêncio Xavier, escritor e jornalista da Gazeta do Povo, de Curitiba, e parente de uma sobrinha de Nhô Totico, sabedor de que eu era um estudioso da memória do rádio - mas, por outro lado, ignorando todos os fatos relatados até aqui -, sugeriu que eu examinasse alguns papéis e objetos do arquivo de Nhô Totico, uma vez que a viúva do artista desejava confiar o material a alguém que pudesse utilizá-lo de modo adequado.

Visitei a casa em que Nhô Totico morou nos seus últimos anos e estive no quartinho dos fundos em que ele guardava seus livros e muitas de suas lembranças: cartas de pessoas com quem ele se correspondia freqüentemente e de profissionais do rádio em diferentes épocas, bem como cópias das respostas, datilografadas pelo próprio Nhô Totico. Em uma pasta que continha ofícios referentes às suas atividades como funcionário público, Nhô Totico escrevera, do próprio punho, a seguinte observação: "Documentos referentes à minha vida de 'Barnabé' do Estado, onde sempre marquei passo por ter a espinha dura e por pensar alto. Ass. Vital Fernandes da Silva". Ha- via, também, recortes do Diário Oficial do Estado. Um deles registra a contagem extra de tempo de serviço para efeito de aposentadoria, por ter ele lutado na Revolução Constitucionalista. Continuando a busca, encontrei fotos de amadores, mostrando Nhô Totico ao lado de familiares e amigos, além de fotos de profissionais em diversas poses, cujas cópias eram distribuídas aos fãs. Mas a documentação fotográfica que mais me chamou a atenção foi a série em que ele aparece com seus companheiros de farda em diferentes locais, bem como alguns instantâneos dos soldados paulistas na frente de combate. Por último, localizei várias gravações de entrevistas, registradas ao longo de sua carreira, além de trechos de seus programas, revividos por ele tal e qual haviam sido transmitidos originalmente.

Nhô Totico representa um capítulo singular da "Era de Ouro" do nosso rádio. Primeiro, pelo fato de jamais desvirtuar o conteúdo de seus programas. Em segundo lugar, por ter explorado as possibilidades do rádio como poucos o fizeram. E, finalmente, porque durante toda a vida orgulhou-se de ser, tão-somente, um artista de rádio.

\section{Relíquia da “ERa de Ouro do RÁdio”}

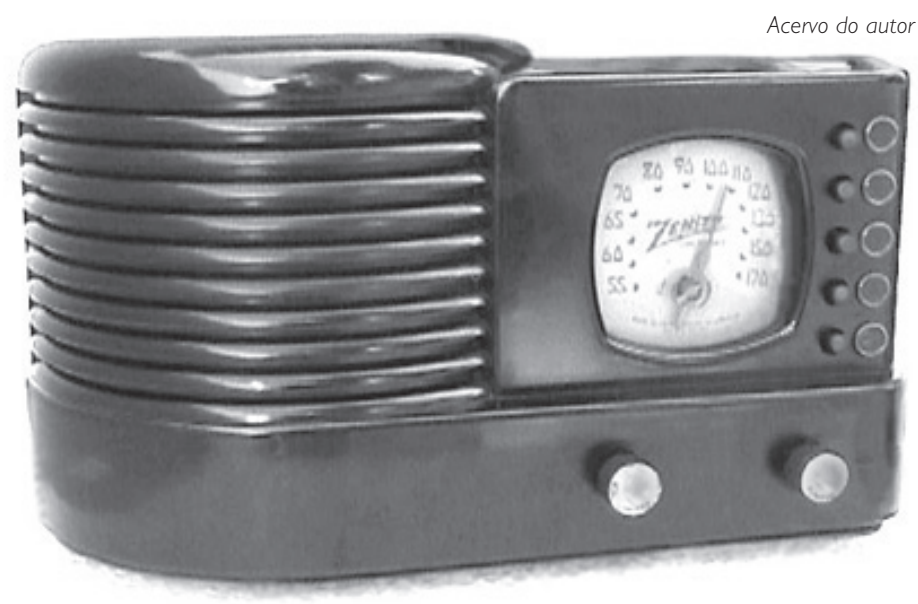

Este aparelho - um Zenith, modelo 5R312 -, fabricado em 1938, possuía apenas uma faixa de onda, mas dispunha de um mecanismo para sintonizar automaticamente até quatro estações, previamente programadas, por meio dos botões que aparecem à direita do dial (o quinto botão liberava o ponteiro para permitir a sintonia manual das demais emissoras). O gabinete de baquelite, de pequenas dimensões (31×18x15 cm), se comparado aos rádios com duas faixas de onda da época, era uma das características dos receptores lançados quando já se preconizava o uso individual dos receptores - ou "um rádio para cada cômodo da casa". A propósito, o aparelho aqui reproduzido funciona até hoje 


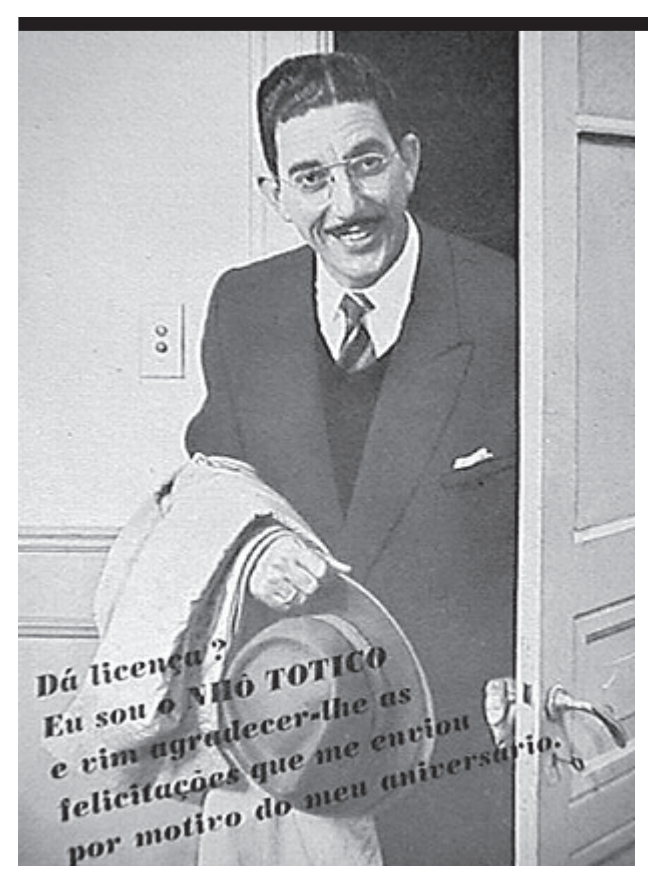

Acima, reprodução de um cartão enviado por Nhô Totico a seus fãs.

Da mesma forma que a maioria dos artistas da época, ele não descuidava do contato, através do correio, com uma verdadeira legião de admiradores

Nнô Toтico, 1903-1995

Fotos do Acervo de Nhô Totico

Vital Fernandes da Silva - "Nhô

Totico" - no apogeu de sua carreira e nos últimos anos de vida
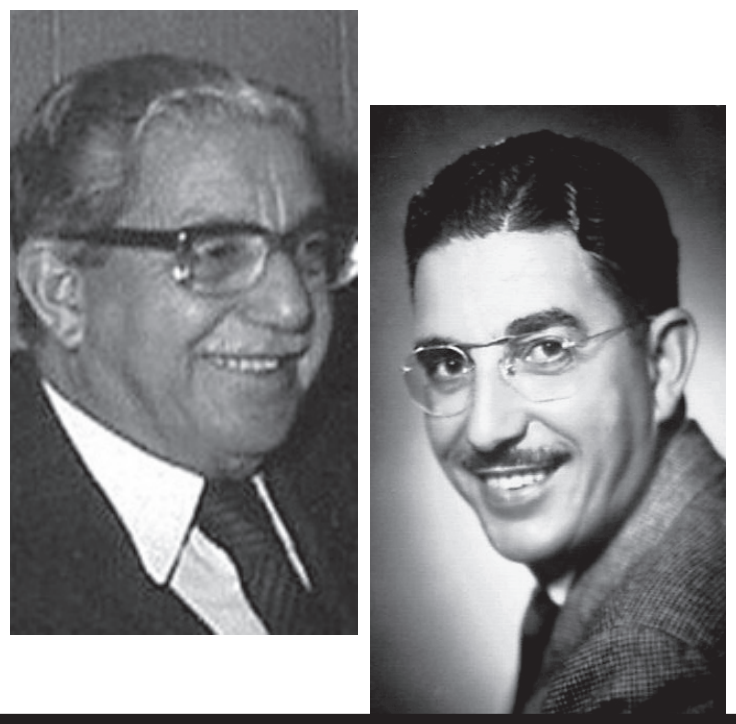

Nhô Totico na Revolução Constitucionalista

Fotos do Acervo de Nhô Totico

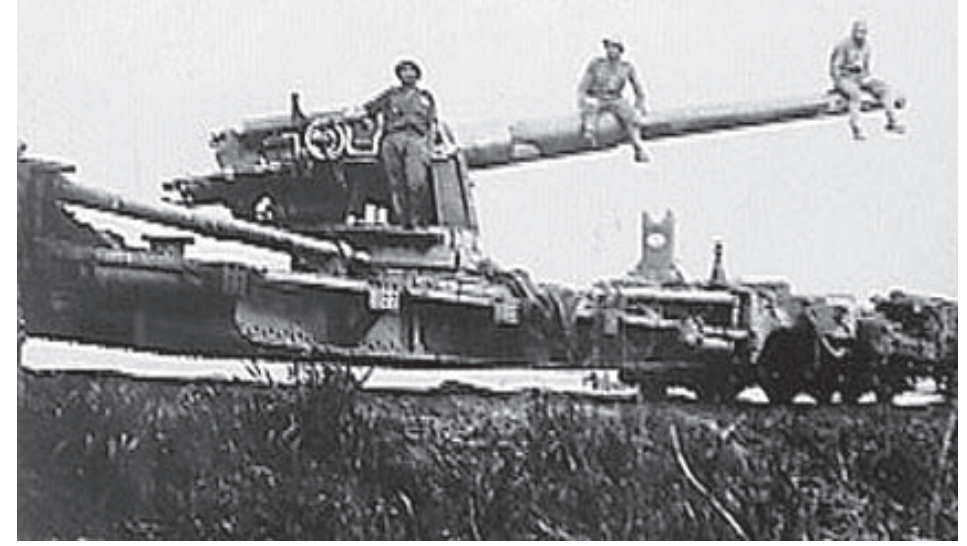

Soldados paulistas exibem seu armamento no Vale do Paraíba. Nhô Totico, que não aparece na foto, estava entre os voluntários

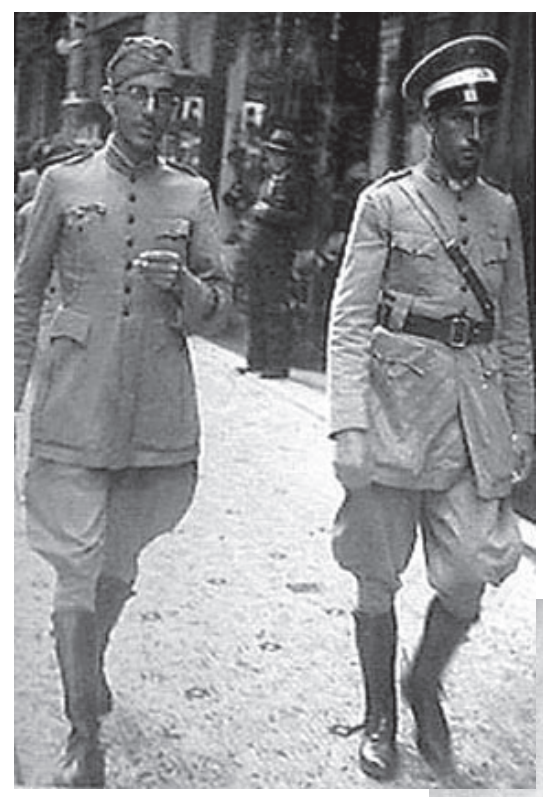

Nhô Totico

(à esquerda), ao lado de outro voluntário da Revolução, passeia numa das ruas centrais de São Paulo

Nhô Totico (à direita) e um companheiro de farda posam para a posteridade, nas escadarias do Monumento do Ipiranga

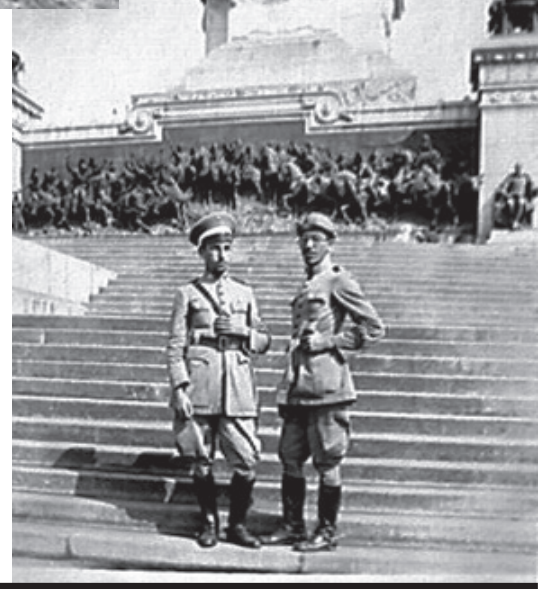

